\title{
Üniversite Öğrencilerinin Yaşam Doyumları Üzerinde Yetersizlik Duygusunun Yordayıcı Etkisi: Sosyal İlginin Aracı Rolü*
}

\author{
Predictive Effects of Feeling of Inferiority on Life Satisfaction in
}

University Students: The Mediating Role of Social Interest

\begin{tabular}{l}
\hline \\
\hline Yazar Bilgileri \\
\hline İrem Fırat@ \\
Yüksek Lisans Öğrencisi, Düzzos \\
Üniversitesi, Sosyal Bilimler \\
Enstitüsü, Rehberlik ve \\
Psikolojik Danısmanlık, \\
iremfirattt@gmail.com \\
Abdi Güngör@ \\
Dr. Öğr. Üyesi, Düzce \\
Üniversitesi, Düzce Eğitim \\
Fakültesi, Rehberlik ve \\
Psikolojik Danışmanlık, \\
abdigungor@duzce.edu.tr
\end{tabular}

\section{İrem Frrat, Abdi Güngör}

\section{ÖZ}

Yaşam doyumu, sağlığın ve ruh sağlı̆̆ının önemli göstergelerinden biridir. Üniversite dönemi, hem öğrencilerin içinde bulundukları gelişim dönemi hem de sonraki dönemlere olan etkisi bakımından zor ve önemli bir süreçtir. Dolayısıyla üniversite öğrencilerinin yaşam doyumlarını etkileyen faktörlerin araştırılması, onların yaşam kalitesini arttırmak açısından önem arz etmektedir. Bu araştırmanın amacı üniversite öğrencilerinin yaşam doyumları üzerinde Bireysel Psikoloji kuramında özellikle vurgulanan yetersizlik duygusunun ve sosyal ilginin yordayıcı etkisi incelemektir. Ayrıca bu araştırmada sosyal ilginin yetersizlik duygusu ve yaşam doyumu arasındaki aracı rolü de incelenmiştir. Araştırmanın çalışma grubunu toplam 371 gönüllü üniversite öğrencisi oluşturmaktadır. Araştırmada veri toplamak amacıyla Demografik Bilgi Formu, Toplumsal İlgi Ölçeği, Yetersizlik Duygusu Ölçeği ve Yaşam Doyumu Ölçeği kullanılmıştır. Araştırmada öne sürülen hipotezleri test etmek için Pearson momentler çarpım korelasyon katsayısı, hiyerarşik regresyon analizi ve yeniden örnekleme yöntemi (bootstrapping) yapılmıştır. Hiyerarşik regresyon analizi sonuçlarına göre yetersizlik duygusu negatif ve sosyal ilgi pozitif yönde yaşam doyumunu anlamlı şekilde yordamıştır. Yeniden örnekleme yöntemi ile yapılan analizlerin sonucuna göre ise sosyal ilginin kısmi bir aracı rol oynadı̆̆ bulunmuştur. Araştırma soncunda elde edilen bulgular kuramsal ve alanyazındaki çalışmalar açısından tartışılmış ve gelecekte yapılacak araştırmalara yönelik öneriler sunulmuştur.

\begin{tabular}{|c|c|}
\hline Makale Bilgileri & ABSTRACT \\
\hline Anahtar Kelimeler & Life satisfaction is one of the most important indicators of the physical health and mental \\
\hline Yetersizlik Duygusu & health. University period is an important time in terms of both students' developmental \\
\hline Sosyal İlgi & tasks and its effects on later developmental stages. Therefore, it is crucial to investigate the \\
\hline Yaşam Doyumu & factors affecting the life satisfaction of university students in terms of enhancing their quality \\
\hline Üniversite Öğrencileri & of life. This study examined the predictive effects of feeling of inferiority and social interest, \\
\hline Aracı Etki & $\begin{array}{l}\text { which are highly emphasized by Individual Psychology, on life satisfaction in } \\
\text { undergraduate students. This study also examined the mediating role of social interest in the }\end{array}$ \\
\hline Keywords & association between feeling of inferiority and life satisfaction. The study group consisted of \\
\hline Feeling of Inferiority & 371 volunteer undergraduate students. Demographic Questionnaire Form, Social Interest \\
\hline Social Interest & Index, Inferiority Feeling Scale, and Satisfaction with Life Scale were used to collect the data. \\
\hline Life Satisfaction & To test the hypothesis, Pearson moments correlation coefficients, hierarchical regression \\
\hline University Students & analyses, and bootstrapping methods were performed. The results of hierarchical regression \\
\hline Mediating Effect & $\begin{array}{l}\text { analyses revealed that feeling of inferiority negatively and social interests positively } \\
\text { predicted life satisfaction. Bootstrapping analysis showed that social interest played a partial }\end{array}$ \\
\hline Makale Geçmişi & mediation role. The findings of this study were discussed along with the implications for \\
\hline Geliş: 27.11.2020 & future studies and professionals to enhance undergraduate students' life satisfaction. \\
\hline
\end{tabular}

Düzeltme: 19.03.2021

Kabul: 03.04.2021

*Bu çalışma 24-26 Haziran 2020 tarihinde düzenlenen I. Uluslararası Pedagojik Araştırmalar Kongresi'nde (ICOPR'20) tamamı yayınlanmadan sözlü bildiri olarak sunulmuştur. 


\section{Giriş}

Dünya Sağlık Örgütünün tanımına göre, ideal sağlığın tanımı bireyin fiziksel, sosyal ve psikolojik işlevleri ile yaşam kalitesini içermektedir (World Health Organization [WHO], 1998). Bu bağlamda yaşam doyumu bireyin sağlıklı oluşunun göstergelerinden birisidir. Alanyazın incelendiğinde kişinin iyi oluşunun öznel iyi oluş, mutluluk, haz, yaşam doyumu, yaşam kalitesi gibi kavramlarla tanımlandığ1 görülmektedir (Güler ve Dönmez, 2011). Diener'in (1984, 2000) iyi olma modeline göre, yaşam doyumu iyi olmanın bilişsel sürecini içerir. Benzer şekilde, Suldo ve Huebner'e (2006) göre yaşam doyumu, kişinin tüm yaşamı veya yakın çevresindeki memnuniyet derecesini gösteren genel bilişsel yargılamalarıdır. Dolayısıyla yaşam doyumu, yaşama yönelik beklentiler ve bu beklentilerden memnun olma düzeyi ile açıklanabilen, iyi olmanın bilişsel boyutunu içeren bir kavramdir.

Alanyazın incelendiğinde yaşam doyumunun benlik saygısı (Diener ve Diener, 2009), olumlu gelecek beklentisi (Eryılmaz, 2011), iyimserlik ve mutluluk (Sapmaz ve Doğan, 2012), psikolojik dayanıkl1lık (Limonero, Tomás-Sábado, Fernández-Castro, Gómez-Romero ve Ardilla-Herrero, 2012), okul iklimi (Suldo, Thalji-Raitano, Hasemeyer, Gelley ve Hoy, 2013), yaşamda anlam (Yıkılmaz ve Demir-Güdül, 2015), duygusal zeka (Özdemir ve Dilekmen, 2016), öğretmen desteği (Guess ve McCane-Bowling, 2016) ve umut (Güngör ve Avc1, 2017) gibi olumlu algilanan pozitif değişkenler ile pozitif yönde ilişkili olduğunu görülmüştür. Diğer taraftan ise yaşam doyumunun, yalnızlık (Goodwin, Cook ve Yung, 2001), depresyon (Jenkins, Belanger, Connally, Boals ve Duron, 2013), depresif belirtiler (Moksnes, Lohre, Lillefjell, Byrne ve Haugan, 2014), stres (Holinka, 2015), sosyal kaygı (Kermen, Tosun ve Doğan, 2016) ve yalnızlık düzeyi (Özkaya, 2017) ile negatif yönde ilişkili olduğu görülmüştür. Sonuç olarak daha önceki çalışmalar yüksek yaşam doyumunun bireyin ruh sağlığı, uyumu ve akademik başarısı açısından önemini ortaya koymuştur.

Üniversite dönemi, öğrencilerin hem ilk yetişkinlik dönemlerini şekillendiren hem de ilerleyen dönemlere geçiş için basamak görevi gören bir adaptasyon sürecidir. Bu nedenle üniversite öğrencilerinin yaşam doyumları, içinde bulundukları dönem açısından olduğu kadar gelecek dönemler açısından da önem arz etmektedir. Üniversite öğrencileri üzerinde daha önce yapılan çalışmalarda, öğrencilerin yaşam doyumları ile ailesel bütünlük duygusu ve benlik saygısı (Çeçen, 2008), yüksek sosyo-ekonomik statü (Özgür, Gümüş ve Durdu, 2010) ve öz-duyarlığın olumlu alt boyutları olan öz sevecenlik, bilinçlilik ve paylaşımların farkında olma (Tel ve Sarı, 2016) ile pozitif yönde ilişkili bulunmuştur. Diğer taraftan üniversite öğrencilerinin yaşam doyumlarının stres (Kaya, Tansey, Melekoğlu ve Çakıroğlu, 2015) ve öz-duyarlığın olumsuz alt boyutları olan öz yargılama, izolasyon ve aşırı özdeşleşme (Tel ve Sarı, 2016) ile negatif ilişkili olduğunu görülmektedir. Ayrıca üniversite öğrencilerinin yaşam doyumunu etkileyen değişkenlerin incelenmesi, bu değişkenlere 
yönelik önleyici ya da iyileştirici psikolojik danışmanlık ve rehberlik hizmetlerine katkı sağlayacaktır (Yiğit, 2012).

Bu çalışmada önce yaşam doyumu düzeyini etkileyebileceği düşünülen yetersizlik duygusu ve sosyal ilgi kavramlarının yaşam doyumu ile ilişkileri incelenmiştir. Yetersizlik ve sosyal ilgi kavramları Alfred Adler'in geliştirdiği Bireysel Psikoloji kuramında ele alınan kavramlardır (Adler, 2008; Ansbacher ve Ansbacher, 1956). Adler kuramının temelini yetersizlik duygusuna dayandırmakta ve bu duyguyla başa çıkmada sosyal ilginin önemini vurgulamaktadır. Dolayısıyla hem yetersizlik duygusu hem de sosyal ilgi kavramı, Adler'e göre ruh sağlığı açısından belirleyici faktörlerdir. Bu nedenle, bu çalışmada üniversite öğrencilerinin yaşam doyumları üzerinde yetersizlik duygusunun ve sosyal ilgi düzeyinin etkisi ele alınmıştır.

\section{Yetersizlik Duygusu}

Bireysel Psikoloji kuramının anahtar kavramlarından biri yetersizlik-aşağılık duygusudur. Yetersizlik duygusu bazı kaynaklarda, aşağılık duygusu olarak da ele alınmaktadır. Bireysel Psikoloji kuramına göre, bireyin erken yaşam döneminde maruz kaldığı olumsuzluklar, onun yaşamla baş edemeyeceği yönünde bir algı oluşturmasına neden olur. Yetersizlik duygusu bireyin hedefe yönelik davranışlarının temelini oluştururken bu hedeflere ulaşması için güdüleyici bir etki de yaratır (Adler, 2008). Yaşamda karşılaştı̆̆ı problemler bireyin tetikte olmasını ve eksikliğini tamamlayıcı davranışlar sergilemesini sağlar (Adler, 2009a). Birey kendini ne kadar aşağıda görürse üstünlük için göstereceği çaba da o kadar artacaktır. Ancak aşağılık duygusunun fazla yaşanması bazen ters bir etki yaratarak bireyin aşağılık kompleksi geliştirmesine ve üstünlük için çabalamak yerine çaresizlik hissetmesine neden olabilir (Burger, 2006).

Alanyazın incelendiğinde yetersizlik duygusunun depresif ve psikotik nitelikler taşıma (Moritz, Werner ve Collani, 2006), yetişkin bağlanma stillerinin alt boyutlarından kaygılı ve kaçınmacı bağlanma (Ekşi, Sevim ve Kurt, 2016), saldırganlık düzeyi (Kızıltaş, 2016), aşağıllık kompleksi (Kalaivani, 2017), kendini saklama ve yalnızlık (Çimşir ve Akdoğan, 2019) ile pozitif yönde ilişkili olduğu görülmektedir. Diğer taraftan yetersizlik duygusunun yaşam kalitesi (Bozkurt, 2019) ile negatif yönde ilişkili olduğu bulunmuştur.

Ülkemizde üniversite öğrencileri üzerinde yetersizlik duygusu üzerine sınırlı sayıda çalışma olmasına rağmen Akdoğan, Aydın ve Eken'in (2018) yakın ilişki sorunları nedeniyle psikolojik yardım almak isteyen 154 üniversite öğrencisiyle yürüttüğü bir çalışmada, normal olmayan aşağılık duygusunun hem kaygılı hem de kaçınmacı bağlanma stilini yordadığı bulunmuştur. Strano ve Petrocelli'nin (2005) bir çalışmasında ise düşük yetersizlik duygusuna sahip olanların akademik başarılarının yüksek olduğunu bulunmuştur. 
Sonuç olarak, bireylerdeki yetersizlik duygusunun ruhsal soruların ortaya çıkmasına neden olabilecek bir değişken olduğu düşünülmektedir (Akdoğan, 2012). Gerek teorik gerekse alanyazındaki çalışmaların gösterdiği gibi yetersizlik duygusu, ruh sağlığını ve yaşam kalitesini tehdit eden bir duygudur. Dolayısıyla yetersizlik duygusu ile yaşam doyumu arasındaki ilişkinin araştırılması, ruhsal sağlığın korunması noktasında hem uygulama da hem de alanyazına katkı sağlayacaktır. Bu bağlamda, kuramsal temel açısından ve alanyazına göre yetersizlik duygusunun yaşam doyumunu negatif yönde yordaması beklenmektedir.

\section{Sosyal İlgi}

Adler'e göre sosyal ilginin kesin bir tanımını yapmak güçtür. Sosyal ilgi tüm insanlarda, farklı düzeylerde var olan bir kavramdır (Ansbacher ve Ansbacher, 1956). Bireyin sosyal ilgisi yakın çevresini veya tüm insanlığı kapsayabileceği gibi canlı ve cansız nesneleri de içerebilir (Gençtan, 2006). Sosyal ilginin veya sosyalliğin temelinde insanın yetersizlik duygusu ve bu yetersizlik duygusunu başkaları ile giderme isteği yatmaktadır. Adler'e göre yetersiz bir canlı olarak doğan birey, çevresindekilerin ilgi ve değerleriyle gelişim gösterir (Ansbacher ve Ansbacher, 1956). Birey bu gelişim sürecinde hem dünyaya uyum sağlamaya çalışmaktadır hem de iş birliği ve ortak yaşamın devamlılığına katkıda bulunmayı öğrenmektedir. Bu yanıyla sosyal ilgi kavramı, birey için toplumdan almayı da topluma vermeyi de içeren iki yönlü bir süreç olarak kabul edilmektedir (Adler, 2004; Soyer, 2001). Bireylerin psikolojik sağlığı için gerekli görülen sosyal ilgi düzeyi hem diğerleriyle sağlıklı bağların kurulmasını hem de ayrı bir birey olma yeteneğinin sürdürülmesini sağlayan optimum düzeyde bir sosyal ilgidir (Johnson, Smith ve Nelson, 2003).

Alanyazın incelendiğinde sosyal ilginin iç-dış kontrol ve kendini gerçekleştirme (Hjelle, 1975), umut ve iyimserlik (Barlow, Tobin ve Schmidt, 2009), psikolojik dayanıklılık ve alt boyutlarından kendini adama, kontrol, meydan okuma ile pozitif yönde ilişkili olduğu bulunmuştur (Kayacı ve Özbay, 2016). Diğer yandan sosyal ilginin, sabırsızlık-saldırganlık ve yıkıcı davranışlar sergileme (Edwards ve Ken, 1995), narsizm ve güç ihtiyacı (Joubert, 1998), depresyon (Saunders ve Roy, 1999) ile negatif yönde ilişkili olduğu bulunmuştur. Ek olarak sosyal ilginin duygusal istismar ve fiziksel istismar ile negatif yönde, soruna yönelme ile pozitif yönde ilişkili olduğu bulunmuştur (Kalkan, 2010).

Ruhsal açıdan problem yaşayan pek çok kişinin toplumsal bütünün bir parçası olamadığı dolayısıyla da sosyal ilgisinin gelişmediği söylenebilir (Adler, 2004). Ek olarak sosyal ilgi düzeyinin ruh sağlığını yordama ve anlamlandırma gücünün yanında; olumlu duygular ve pozitif bir benlik algısı geliştirme gibi değişkenlerle de ilişkili olduğu görülmektedir (Barlow vd., 2009; Hjelle, 1975; Kayacı ve Özbay, 2016). Bu açıdan bakıldığında, sosyal ilgi düzeyinin yaşam doyumu ile pozitif 
yönde ilişkili olduğu düşünülmektedir. Bireylerin yüksek sosyal ilgiye sahip olmalarının, onların daha fazla yaşam doyumuna sahip olacağı kuramsal olarak beklenmektedir.

\section{Sosyal İlginin Aracı Rolü:}

Aracı değişken, bağımsız değişken(ler) ile bağımlı değişken(ler) arasındaki ilişkiyi açıklayan ve bu iliş̧kinin nasıl olduğunu açıklayan bir değişkendir (Preacher ve Hayes, 2004, 2008). Hem kuramsal olarak hem de alanyazındaki çalışmalara göre, yetersizlik duygusu ve sosyal ilginin, yaşam doyumunun anlamlı bir yordayıcısı olması beklenmektedir. Bunun yanında yetersizlik duygusu ile sosyal ilgi arasında da bir ilişki olduğu öngörülmektedir. Nitekim Adler'e (2009b) göre bireyi sürekli tetikleyen aşağılık duygusuyla baş edebilmek, bireyin değerli olduğu bilgisi ve hissine sahip olmasından geçer. Bunu sağlayabilmenin yolu da toplumun ortak paydasına katkıda bulunmaktır. Buna bağlı olarak yüksek yetersizlik duygusunun düşük sosyal ilgiyi, düşük sosyal ilginin de düşük yaşam doyumunu yordaması beklenmektedir.

Sonuç olarak, bu çalışmada üniversite öğrencilerinin yaşam doyumları üzerinde yetersizlik duygusunun ve sosyal ilgilinin yordayıcı etkisi incelenmektedir. Yaşam doyumu bireylerin hayatının her döneminde olduğu gibi üniversite döneminde de oldukça önemlidir. Ergenlik döneminin bitişi ile yetişkinlik döneminin başlangıcı olarak görülen bu geçiş sürecinde, bireyler diğer dönemlere göre daha fazla stres ve kaygı yaşayabilmektedir (Meadows, Brown ve Elder, 2006). Çünkü bu dönem bireylerin bağımsız bir kimlik edinme, mesleki kararlar üzerinde yoğunlaşma ve yakın ilişkiler geliştirme gibi sonraki dönemler üzerinde kritik etkileri olan süreçlerle doludur (Rickwood, Deane, Wilson ve Ciarrochi, 2005). Kısacası, üniversite dönemi hem ilk yetişkinlik dönemi olması hem de ilerleyen dönemler açısından önem arz etmesi bakımından önemli bir geçiş dönemidir. Dolayısıyla öğrencilerin yaşam doyumunu etkileyecek faktörlerin araştırılması, onların yaşam kalitesi ve akademik başarıları açısından önleme ve müdahale hizmetlerinin geliştirilmesine hizmet edecektir. Bunu yanında sosyal ilginin yetersizlik duygusu ve yaşam doyumu arasındaki aracı rolünün anlaşılması da sosyal ilgilinin merkezi rolünün anlaşılmasına katkı sağlayacaktır.

\section{Yöntem}

\section{Araştırma Grubu}

Araştırma grubu, araştırmacılar tarafından online olarak ulaşılan, 17-46 yaş aralığındaki $(\bar{x}=21.9 ; S=3.4)$ üniversite öğrencilerden oluşmaktadır. Katılımcıların yaş aralığı geniş olarak görünse de yaş ortalaması (21.9) ve sapma değeri (3.4) katılımcıların ortalama ilk yetişkinlik döneminde olduğunu göstermektedir. Araştırmaya 85 erkek $(\% 22,9)$ ve 286 kadın $(\% 77,1)$ olmak üzere toplam 371 gönüllü öğrenci katılmıştır. Katılımcıların \%12,7'si birinci sınıfta, \%12,9'u ikinci sınıfta, \%21,6'sı üçüncü sınıfta ve \%52,8'i dördüncü sınıfta öğrenim görmektedir. 


\section{Veri Toplama Araçları}

\section{Demografik Bilgi Formu:}

Araştırmacılar tarafından hazırlanan demografik bilgi formu, araştırma grubunu oluşturan üniversite öğrencilerinin cinsiyeti, yaşı, sınıf düzeyi ve sosyoekonomik durumuyla ilgili bilgileri içermektedir.

\section{Toplumsal İlgi Ölçeği (TíÖ):}

Ölçeğin orijinali Greever, Tseng ve Friedland (1973) tarafından geliştirilmiştir. Ölçeğin Türkçeye uyarlaması ve geçerlik, güvenirlik çalışması Soyer (2004) tarafından 400 üniversite öğrencisiyle yapılmıştır. Ölçeğin Türk kültüründe toplumsal ilgiyi tam olarak ölçmediği düşünüldüğü için, orijinali 32 maddeden oluşan ölçek uzman görüşleriyle 52 maddeye çıkartılmıştır. Ölçeğin güvenirliğini saptamak için yapılan analizlerde Cronbach Alfa iç tutarlık katsayısı .88 ve test tekrar test güvenirlik katsayısı .82 olarak bulunmuştur. Bireyler ölçeği cevaplarken "tümüyle uygun", "genellikle uygun", "kısmen uygun" ve "hiç uygun değil" seçeneklerinden kendilerine en uygun olan ifadeyi işaretlemektedir. Toplumsal İlgi Ölçeği'nden 0-208 puan arasında, tek bir toplam puan elde edilmektedir. Ölçekten alınan yüksek puan, toplumsal ilgi düzeyinin yüksekliğini; düşük puan ise, toplumsal ilgi düzeyinin düşüklüğünü göstermektedir. Bu çalışmada iç tutarlılık katsayısı .91 olarak bulunmuştur, bu da ölçeğin yüksek düzeyde güvenilir olduğunu göstermektedir (Pallant, 2010).

\section{Yetersizlik Duygusu Ölçeği (YDÖ):}

Üniversite öğrencilerinin yetersizlik duygularını ölçmek amacıyla Akdoğan ve Ceyhan (2014) tarafından geliştirilen Yetersizlik Duygusu Ölçeği (YDÖ) 20 maddelik bir ölçektir. Ölçeğinin güvenirliğini saptamak için yapılan analizlerde, Cronbach Alfa iç tutarlık katsayısı .86 ve test tekrar test güvenirlik katsayısı .88 olarak bulunmuştur. Test yarılama yöntemiyle yapılan analizde ise her iki yarınında iç tutarlılık katsayısı .76 olarak bulunmuştur. Yapılan faktör analizi sonucunda 20 maddeden oluşan üç boyutlu bir yapı ortaya çıkmıştır. Bu yapılar "Cesaretin Kırılması", "Kendi Değerini Yadsıma" ve "Yararsız Üstünlük Çabası"dır. Bireyler ölçekte yer alan her madde için “her zaman (5)", "sık sik (4)", “ara sıra (3)", "nadiren (2)" ve "hiçbir zaman (1)" seçeneklerinden kendilerine en uygun olan ifadeyi işaretlemektedir. Yetersizlik Duygusu Ölçeği'nden alınan toplam puanlar 20-100 arasındadır. Bu çalışmanın amacına uygun olarak sadece toplam puan kullanılmıştır. Ölçekten alınan yüksek puan, bireyin daha fazla yetersizlik duygusuna sahip olduğunu göstermektedir. Bu çalışmada .83 olarak bulunan YDÖ’nün iç tutarlılık katsayısı ölçeğin güvenilir bir ölçek olduğunu göstermektedir (Pallant, 2010). 


\section{Yaşam Doyumu Ölçeği:}

Ölçeğin orijinali Diener, Emmons, Larsen ve Griffin (1985) tarafından geliştirilmiştir. Ölçeğin orijinali bir faktör, beş maddeden oluşan ve 7'li Likert tipi bir ölçektir. Ölçek önce Köker (1991) tarafından Türkçeye uyarlanmıştır. Fakat Dağlı ve Baysal (2016) daha sonra yaptıkları çalışmada ölçeği 5'li Likert tipinde uyarlamışlardır. Ölçeğin Cronbach Alpha iç tutarlık kat sayısı .88 ve test tekrar test güvenirlik katsayısı ise .97 olarak saptanmıştır. Yapılan faktör analizi sonuçları, Yaşam Doyumu Ölçeği'nin tek faktörlü bir yapı gösterdiğini ve 5 maddeden oluştuğunu göstermiştir. Bireyler ölçekte yer alan her madde için "tamamen katılıyorum", "büyük oranda katılıyorum", "orta düzeyde katılıyorum", "çok az katılıyorum" ve "hiç katılmıyorum" seçeneklerinden kendilerine en uygun olan ifadeyi işaretlemektedir. Bu çalışmada iç tutarlılık katsayısı .80 olarak bulunmuştur, bu da ölçeğin güvenilir olduğunu ortaya koymaktadır (Pallant, 2010).

İşlem

Veri toplama sürecinden önce araştırma için etik kurul izni alınmıştır. Araştırmada kullanılan ölçme araçları online bir platforma aktarılmış ve online link katılımcılarla paylaşılmıştır. Araştırmanın başında, katılımcılara araştırmanın önemi ve soruları nasıl cevaplayacaklarıyla ilgili gerekli açıklamalar paylaşılmıştır ve araştırmaya katılmaya gönüllü olup olmadıklarına dair bir soru sorulmuştur. Veri toplama sürecinde katılımcı adı, soyadı veya öğrenci numarası gibi kişisel bilgiyi ortaya çıkaracak herhangi bir soru sorulmamıştır. Verilerin analizinde SPSS 22.0 paket programı kullanılmıştır. Araştırmanın bulgularını yorumlamada .05 anlamlılık düzeyi temel alınmıştır.

Verilerin analizi iki aşamada gerçekleştirilmiştir. İlk aşamada veri setinin uygulanacak olan istatistiksel yöntemlere uygunluğu test edilmiştir. İkinci aşamada ise bağımsız değişkenlerin (yetersizlik duygusu ve sosyal ilgi) bağımlı değişkeni (yaşam doyumu) yordamasını test etmek amacıyla hiyerarşik regresyon analizi yapılmıştır. Ayrıca sosyal ilginin yetersizlik duygusu ve yaşam doyumu arasındaki aracı rolü, Preacher ve Hayes $(2004,2008)$ tarafından geliştirilen SPPS-macro programı ile yeniden örnekleme yöntemi (bootstrapping) kullanılarak 10.000 tekrarlı denemeyle (iteration) test edilmiştir.

Analizlere geçilmeden önce, uç değerler, normallik, değişkenler arasında çoklu bağlantı (multicollinearity), varyans genişlik faktörü (VIF) ve tolerans değerleri incelenmiştir. Mahalonobis uzaklık değerleri incelenmiştir ve herhangi bir uç değere rastlanmamıştır. Normallik açısından, çarpıklık (skewness) değerlerinin -.03 ile -.44 arasında, basıklık (kurtosis) değerlerinin ise -.01 ile .14 arasında değiştiği gözlenmiştir. Bu sonuçlar da veri setinin normal dağıldı̆̆ını desteklemektedir (Pallant, 2010; Tabachnick ve Fidell, 2013). Verilerin VIF değerlerinin 10'dan küçük olduğu ve tolerans seviyelerinin de .10 'dan büyük olduğu saptanmıştır. Ayrıca bağımsız değişkenler arasındaki ilişkinin 
-.19 olduğu bulunmuştur. Bu sonuçlara göre bağımsız değişenler arasında çoklu bağlantı probleminin olmadığı tespit edilmiştir. Sonuç olarak veri setinin gerekli varsayımları karşıladığı görülmüştür.

\section{Bulgular}

Değişkenler arasındaki ilişki Pearson Momentler Çarpım Korelasyon Katsayısı ile incelenmiş̧tir (Tablo 1). Korelasyon sonuçlarına göre yaşam doyumu, yetersizlik duygusu ile negatif yönlü anlamlı bir ilişkiye $(r=-.39, p<.01)$ sosyal ilgi ile ise pozitif yönlü anlamlı bir ilişkiye $(r=.22$, $p<.01)$ sahiptir. Yetersizlik duygusu ile sosyal ilgi arasında negatif yönde anlamlı bir ilişki $(r=-.19$, $p<.01$ ) bulunmuştur.

Tablo 1. Yaşam Doyumu, Yetersizlik Duygusu ve Sosyal İlgi Arasındaki İlişkiler

\begin{tabular}{llll}
\hline Değişkenler & $\mathbf{1}$ & $\mathbf{2}$ & 3 \\
\hline Yaşam Doyumu (1) & 1 & & \\
Yetersizlik Duygusu (2) & $-.39^{* *}$ & 1 & \\
Sosyal İlgi (3) & $.22^{* *}$ & $-.19^{* *}$ & 1 \\
${ }^{* *} \mathrm{p}<.01$ & & &
\end{tabular}

Yetersizlik duygusunun ve sosyal ilginin yaşam doyumunu yordayıp yordamadığını anlamak için hiyerarşik regresyon analizi yapılmıştır. Hiyerarşik regresyon sonuçları Tablo 2'de verilmiştir. Analizin ilk adımında, yetersizlik duygusu modele girilmiştir. Yetersizlik duygusu yaşam doyumunu negatif yönde anlamlı bir şekilde yordamıştır ve toplam varyansın \%16'sını açıklamıştır. İkinci adımda, sosyal ilgi modele eklenmiştir. Sosyal ilgi yaşam doyumunu pozitif yönde anlamlı bir şekilde yordamışır ve açıklanan toplam varyansa \%2'lik bir katkı yapmıştır. İkinci adımda yetersizlik duygusu ve sosyal ilgi beraber toplam varyansın \%18'ini açıklamıştır. Fakat ikinci adımda sosyal ilgi modele eklenince, yetersizlik duygusunun yaşam doyumu üzerindeki etkisi ikinci adımda $\beta=-.39^{\prime}$ dan $\beta=-.37$ 'ye düşmüştür. Bu sonuçlar sosyal ilginin yetersizlik duygusu ile yaşam doyumu arasında aracı rol etkisine sahip olabileceğini göstermektedir fakat bu etkinin anlamlılık düzeyini belirlemek için daha ileri bir analiz gerekmektedir.

Tablo 2. Yaşam Doyumunun Yordanmasına İlişkin Hiyerarşik Regresyon Analizi Sonuçları

\begin{tabular}{|c|c|c|c|c|c|c|c|c|}
\hline Değişkenler & $R^{2}$ & $\Delta R^{2}$ & B & $\begin{array}{l}\text { Standart } \\
\text { Hata }\end{array}$ & $\beta$ & $t$ & $p$ & $F$ \\
\hline Adim 1 & .16 & & & & & & & $63.36^{* * *}$ \\
\hline Yetersizlik Duygusu & & & -.13 & .02 & -.39 & -7.96 & .000 & \\
\hline Adım 2 & .18 & $.02^{* *}$ & & & & & & $36.86^{* * *}$ \\
\hline Yetersizlik Duygusu & & & -.12 & .07 & -.37 & -7.34 & .000 & \\
\hline Sosyal İlgi & & & .03 & .01 & .15 & 2.99 & .003 & \\
\hline
\end{tabular}

\section{Sosyal İlgilinin Aracı Etkisine Ait Bulgular}

Baron ve Kenny'e (1986) göre aracı etki analizi için üç şartın sağlanması gerekir. Birinci şarta göre bağımsız değişken (yetersizlik duygusu) aracı değişkeni (sosyal ilgi) yordaması gerekir. İkinci şart ise bağımsız değişkenin bağımlı değişkeni (yaşam doyumu) yordamasıdır. Üçüncü şart ise bağımlı değişkenin bağımsız değişken ve aracı değişken ile beraber yordandığında, aracı değişken 
bağımlı değişkeni yordamalı ve bağımsız değişkenin etkisi ortadan kalkmalı (tam aracı) veya azalmalıdır (kısmi aracı). Hiyerarşik regresyon sonuçlarına göre, ikinci ve üçüncü şartlar halihazırda karşılanmıştır. İlk şart ile ilgili, bir doğrusal regresyon analizi yapılmıştır. Bu sonuçlara göre, yetersizlik duygusu sosyal ilgiyi anlamlı ve negatif yönde yordamıştır $(F(1,348)=12.75, p<.001$; $\beta=-.19, p<.001)$. Sonuç olarak, sosyal ilgi yetersizlik ve yaşam doyumu arasında aracı bir rol oynamıştır.

Şekil 1 yeniden örnekleme yöntemi sonucunda elde edilen katsayı değerlerini göstermektedir. Şekilde yetersizlik duygusundan sosyal ilgiye, sosyal ilgiden yaşam doyumuna ve yetersizlik duygusundan yaşam doyumuna olan doğrudan ve toplam etkiler gösterilmiştir. Yaşam doyumu yordanırken, \%95 güven aralığının sıfır değerini içermediği görülmüştür [-.02 ve -.01 aralığı]. Bu sonuç sosyal ilginin anlamlı bir aracı etkisinin olduğunu göstermektedir. Ayrıca yetersizlik duygusunun yaşam doyumu üzerine olan doğrudan etkisi de anlamlı olduğu için, sosyal ilgi yetersizlik duygusu ile yaşam doyumu arasında kısmi aracı rol oynamıştır.

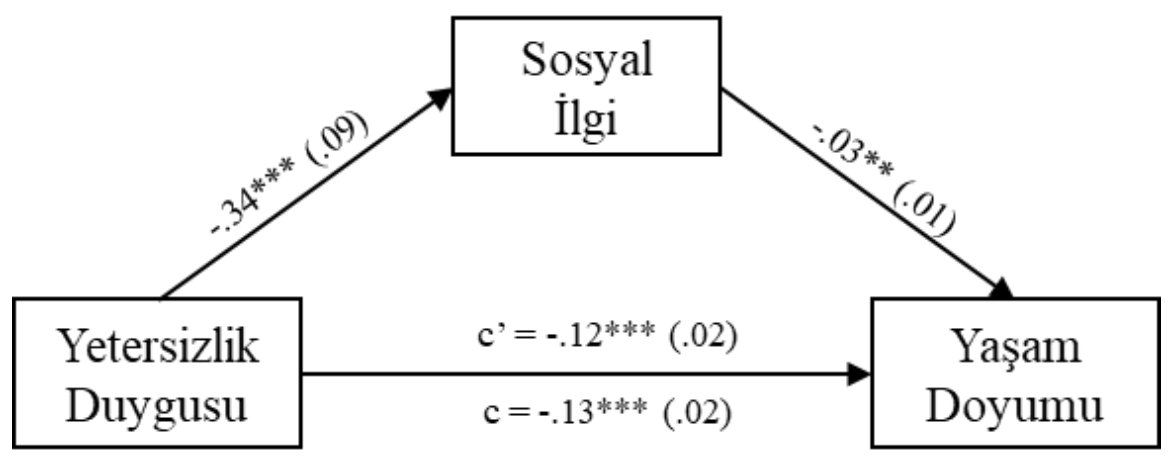

\section{Şekil 1. Sosyal İlginin Yetersizlik ve Yaşam Doyumu Arasındaki İlişkide Aracı Rolü} Bütün etki değerleri standartlaştırılmamış değerlerlerdir ve standart hatalar parantez içinde gösterilmiştir. $\mathrm{c}^{\prime}$ değeri yetersizlik duygusundan yaşam doyumuna olan doğrudan etkiyi göstermekte; c değeri yetersizlik duygusundan yaşam doyumuna olan toplam etkiyi göstermektedir.

\section{Tartışma}

Üniversite dönemi bireylerin yaşamında önemli bir geçiş dönemi görevi görmektedir. Bu sürecin en sağlıklı şekilde geçirilmesi bireylerin iyi oluşuna, ruh sağlığına, akademik başarısına ve gelecek dönemlerin daha sağlıklı geçirilmesine olumlu katkılar sağlayacaktır. Yaşama yönelik algı ve değerlendirmeleri içeren yaşam doyumu kavramı bireyin yaşamının her döneminde ruh sağlığı açısından önem taşımaktadır. Dolayısıyla üniversite öğrencilerin yaşam doyumunu etkileyecek faktörlerin araştırılması onların içinde bulundukları dönemi ve gelecek dönemleri etkilemesi açısından önemlidir.

Yapılan analiz sonuçlarına göre yetersizlik duygusunun yaşam doyumunu negatif yönde anlamlı bir şekilde yordadığı bulunmuştur. Adler'in (2004) kuramına göre doğuştan yetersizlik 
duygusuna sahip olan birey, bu duygusunu ödünlemeye çalışmaktadır. Eğer kişi yetersizlik duygusu ile baş edemezse bu durum kişinin ruh sağlığı ve yaşam kalitesi açısından risk oluşturmaktır (Ansbacher ve Ansbacher, 1956). Kısacası elde edilen sonuçlar, kavramların kuramsal temeli ile de açıklanabilmektedir. Ayrıca çalışmanın bu bulgusu, yetersizlik duygusunun yaşam kalitesi ile negatif yönde ilişkili olduğu araştırma sonuçları ile de tutarlılık göstermektedir (örn., Bozkurt, 2019). Sonuç olarak, bu bulgu bireylerin yetersizlik duygusu arttıkça yaşam doyumlarının azaldığını göstermektedir.

Bu çalışmada, sosyal ilginin yaşam doyumunu pozitif yönde anlamlı bir şekilde yordadığı bulunmuştur. Bu sonuç da Adler'in kuramsal yaklaşımını desteklemektedir çünkü Adler'e göre sosyal ilgi ruh sağlığının ve yaşam kalitesinin önemli göstergelerinden birisidir (Ansbacher ve Ansbacher, 1956). Alanyazında bu bulguyla tutarlılık gösteren doğrudan bir çalışmaya rastlanmamış olmamasına rağmen, çalışmanın bu bulgusu sosyal ilginin sabırsızlık-saldırganlık ve yıkıcı davranışlar sergileme (Edwards ve Ken, 1995), narsizm ve güç ihtiyacı (Joubert, 1998) ve depresyon (Saunders ve Roy, 1999) gibi istenmeyen değişkenler ile negatif yönde ilişkili olduğu araştırma sonuçlarıyla da tutarlılık göstermektedir. Bireylerin düşük sosyal ilgiye sahip olmaları, onların olumuz duygu ve düşünceler taşımalarına dolayısıyla da yaşamlarını olumsuz olarak değerlendirmelerine sebep olabilir. Diğer yandan içinde bulunduğu toplumla karşılıklı bir alışveriş halinde olan bireylerin yaşamları hakkında daha olumlu bir değerlendirmeye sahip olabileceği varsayılabilir.

$\mathrm{Bu}$ çalışmada elde edilen bir diğer bulguya göre, sosyal ilginin yetersizlik ve yaşam doyumu arasındaki ilişkide anlamlı bir kısmi aracı rolünün olmasıdır. Buna göre, yetersizlik duygusunun artması sosyal ilginin düşmesine ve bu durum da yaşam doyumunun azalmasına sebep olmaktadır. $\mathrm{Bu}$ sonuç ayrıca sosyal ilginin yaşam doyumunun yordanmasındaki merkezi rolünü de vurgulamaktadır. Dolayısıyla üniversite öğrencilerinin yaşam doyumunun yükseltilmesinde sosyal ilgiyi arttırmaya yönelik çalışma ve uygulamaların önemli bir fonksiyona sahip oldukları söylenebilir. Buna rağmen sosyal ilginin kısmi aracı rol oynadığı vurgulanmalıdır. Diğer bir ifadeyle, sosyal ilgi model eklendiğinde, yetersizlik duygusunun yaşam doyumu üzerindeki etkisi hala anlamlıdır. Sonuç olarak yetersizlik duygunsun yaşam doyumu üzerindeki doğrudan yordayıcı etkisi, yaşam doyumunu arttırmaya yönelik çalışmalarda hala önem arz etmektedir.

Yetersizlik duygusunu yoğun olarak yaşayan ve yaşama olasılığı yüksek olan üniversite öğrencilerinin belirlenmesi öncelikli olarak kimlere psikolojik yardım sunulması gerektiğinin belirlenmesine yardımcı olabilir. Spesifik olarak yetersizlik duygusunun azaltılmasına yönelik bireysel (bireysel danışma gibi), grup (grupla danışma veya psikoeğitim programları gibi) çalışmaları veya sosyal faaliyetler üniversiteler tarafından organize edilebilir. Bu çalışmada yüksek yaşam doyumunun yordanmasında rol oynayan bir diğer değişken de sosyal ilgidir. 
Adler'e göre sosyal ilgi doğuştan bireyde var olan bir eğilim olmasının yanında geliştirilme potansiyeli de olan bir kavramdır. Bu açıdan bakıldığında eğitim kurumlarında sosyal ilgi odaklı akademik ve sosyal programların tasarlanması, planlı bir çerçevede uygulanması bireylerin yaşam doyumları üzerinde etkili olabileceği düşünülmektedir. Özellikle üniversitelerin Sağlık, Kültür ve Spor Dairesi Başkanlıklarınca (SKS) sosyal ilgiyi artırmaya yönelik aktivite, organizasyon ve sosyodrama etkinliklerine yer verilebilir. Yine benzer şekilde öğrencilerin daha fazla sosyal faaliyetlere katılacağı, öğrenci merkezli kulüp ve öğrenci topluluk faaliyetlerinin desteklenmesi onların kendi yaşamlarına yönelik daha olumlu bir algıya sahip olmalarını destekleyecektir. Bireyin sosyal ilgisinin yüksek olmasının bireye olduğu kadar, bireyin toplumla bütünleşmiş ve etkileşim halinde üretkenlik sunmasıyla da topluma katkı sağlayacağı düşünülmektedir. Dolayısıyla üniversite öğrencilerinin topluma katkı verebilecekleri faaliyetler içinde olmaları, sosyal ilgilerinin artmasına katkı sağlayarak yaşam doyumlarının artmasını destekleyebilir. Bu amaçla toplumdan ayrışmış bireylerin topluma geri kazandırılması veya sosyal sorumluluk kapsamında sosyal ilgi odaklı yapılacak sosyal faaliyetlere öğrencilerin katılımlarının sağlanması da faydalı olabilir.

$\mathrm{Bu}$ çalışma sonucunda önemli bulgulara ulaşılmış olmasına rağmen, bazı sınırlılıklar bulunmaktadır. Öncelikle bu çalışma değişkenler arası ilişkilerin incelendiğĭ, korelasyonel bir araştırmadır. Dolayısıyla bu araştırmanın sonuçları için bir neden-sonuç ilişkisinden bahsetmek doğru olmayacaktır. Bu araştırmada kuramsal varsayımlara dayanarak etkisi olabileceği düşünülen ilişkiler incelenmiştir. Neden-sonuç ilişkilerinin daha iyi anlaşılması için, boylamsal veya deneysel çalışmalar yapılabilir. Ayrıca araştırmada genel bir yetersizlik duygusu ele alınmış olup belli bir alana ait yetersizlik duygusundan bahsedilmemektedir. Sonraki araştırmalarda yetersizlik duygusunun hangi alanda daha baskın olduğu incelenebilir. Araştırmada büyük oranda kadın katılımcıların yer aldığı ve kadın-erkek dengesinin tam olarak sağlanamadığı görülmektedir. Bu dengenin sağlanarak kapsamın genişletilmesi önerilebilir. Ek olarak, verilerin online bir sistem üzerinden toplanması ise herkese ulaşılamamasına neden olmaktadır. Son olarak, bu çalışma üniversite öğrencileri ile sınırlıdır. Bu durum araştırmanın daha sonra farklı bölge ve üniversitelerde, farklı yaş gruplarında da yapılabileceği önerisini ortaya çıkarmaktadır.

\section{Kaynaklar}

Adler, A. (2004). Yaşamın anlam ve amacı. F. T. Verlag (Ed.). (K. Şipal, Çev.). Ankara: Say Yayınları. (Orijinal çalışma basım tarihi 1985).

Adler, A. (2008). Nevroz sorunları. H. L. Ansbacher (Ed.). (A. Kılıçlığlu, Çev.). Ankara: Say Yayınları. (Orijinal çalışma basım tarihi 1964.)

Adler, A. (2009a). Bireysel psikoloji. (A. Kılıçlığlu, Çev.). Ankara: Say Yayınları. (Orijinal çalışma basım tarihi 1918). 
Adler, A. (2009b). İnsanı tanıma sanatı. (K. Şipal, Çev.). Ankara: Say Yayınları. (Orijinal çalışma basım tarihi 1927).

Akdoğan, R. (2012). Adleryen yaklaşıma dayalı grupla psikolojik danışmanın üniversite öğrencilerinin yetersizlik duygusu ve psikolojik belirti düzeylerine etkisi. (Doktora tezi). https://tez.yok.gov.tr sayfasından erişilmiştir.

Akdoğan, R., \& Ceyhan, E. (2014). Üniversite öğrencileri için yetersizlik duygusu ölçeğinin geliştirilmesi: Geçerlik ve güvenirlik analizleri. Türk Psikolojik Danışma ve Rehberlik Dergisi, 5(42), 280-293.

Akdoğan, R., Aydın, M., \& Eken, H. (2018). Understanding the contribution of abnormal inferiority feelings on insecure attachment through gender and culture: A study of university students seeking psychological support. The Journal of Individual Psychology, 74(1), 96-116.

Ansbacher, H. L., \& Ansbacher, R. R. (1956). The individual psychology of Alfred Adler: A systematic presentation in selections from his writings. New York: Basic Books.

Barlow, P. J., Tobin, D. J., \& Schmidt, M. M. (2009). Social interest and positive psychology: Positively aligned. Journal of Individual Psychology, 65(3), 191-202.

Baron, R. M., \& Kenny, D. A. (1986). The moderator-mediator variable distinction in social psychological research: Conceptual, strategic, and statistical considerations. Journal of Personality and Social Psychology, 51(6), 1173-1182.

Bozkurt, R. M. (2019). Üniversite öğrencilerinin yaşam kalitesi ile yakın ilişkilerdeki eğilimleri ve yetersizlik duygusu arasındaki ilişkinin incelenmesi. (Yüksek lisans tezi). https://tez.yok.gov.tr sayfasından erişilmiştir.

Burger, J. M. (2006). Kişilik. (İ. Erguvan-Sarığlu, Çev.). İstanbul: Kaknüs Yayınları.

Çeçen, A. R. (2008). Üniversite öğrencilerinde yaşam doyumunu yordamada bireysel bütünlük (tutarlılık) duygusu, aile bütünlük duygusu ve benlik saygısı. Eğitimde Kuram ve Uygulama, 4(1), 19-30.

Çimşir, E., \& Akdoğan, R. (2019). Yalnızlık ve yetersizlik duygusu arasındaki ilişkide kendini saklamanın aracı rolü. Anadolu Üniversitesi Ĕ̆itim Bilimleri Enstitüsü Dergisi, 9(1), 111-128.

Dağll, A., \& Baysal, N. (2016). Yaşam doyumu ölçeğinin Türkçeye uyarlanması: Geçerlik ve güvenirlik çalışması. Electronic Journal of Social Sciences, 15(59), 1250-1262.

Diener, E. (1984). Subjective well-being. Psychological Bulletin, 95(3), 542-575.

Diener, E. (2000). Subjective wellbeing: The science of happiness and a proposal for a national index. American Psychological Association, 55, 34-43. 
Diener, E., \& Diener, M. (2009). Cross-cultural correlates of life satisfaction and self-esteem. In Culture, 68(4), 653-663.

Diener, E. D., Emmons, R. A., Larsen, R. J., \& Griffin, S. (1985). The satisfaction with life scale. Journal of Personality Assessment, 49(1), 71-75.

Edwards, D., \& Kern, R. (1995). The implications of teachers' social interest on classroom behavior. Individual Psychology: Journal of Adlerian Theory, Research E Practice, 51(1), 67-73.

Ekşi, H., Sevim, E., \& Kurt, B. (2016). Psikolojik doğum sırası ile yetersizlik duygusunun yetişkin bağlanma stillerini yordama düzeyinin incelenmesi. Elementary Education Online, 15(3), 10541065.

Eryılmaz, A. (2011). Ergen öznel iyi oluşu ile olumlu gelecek beklentisi arasındaki ilişkinin incelenmesi. Düşünen Adam: Journal of Psychiatry E Neurological Sciences, 24(3), 209-215.

Gençtan, E. (2006). Psikanaliz ve sonrası. İstanbul: Metis Yayınları.

Goodwin, R., Cook, O., \& Yung, Y. (2001). Loneliness and life satisfaction among three cultural groups. Personal Relationships, 8(2), 225-230.

Greever, K. B., Tseng, M. S., \& Friedland, B. U. (1973). Development of the Social Interest Index. Journal of Consulting and Clinical Psychology, 41(3), 454-458.

Guess, P. E., \& McCane-Bowling, S. J. (2016). Teacher support and life satisfaction: An investigation with urban, middle school students. Education and Urban Society, 48(1), 30-47.

Güler, M., \& Dönmez, A. (2011). İyi olma hali bağlamında uyum düzeyi kuramı ve hedonik döngü. Türk Psikoloji Yazıları, 14(27), 38-47.

Güngör, A., \& Avc1, M. (2017). Examining the relationship between hope and life satisfaction among middle school students. Journal of Pedagogical Research, 1(1), 54-63.

Hjelle, L. A. (1975). Relationship of social interest to internal-external control and self-actualization in young women. Journal of Individual Psychology, 31(2), 171-174.

Holinka, C. (2015). Stress, emotional intelligence, and life satisfaction in college students. College Student Journal, 49(2), 300-311.

Jenkins, S. R., Belanger, A., Connally, M. L., Boals, A., \& Durón, K. M. (2013). First-generation undergraduate students' social support, depression, and life satisfaction. Journal of College Counseling, 16(2), 129-142.

Johnson, P., Smith, A. J., \& Nelson, M. D. (2003). Predictors of social interest in young adults. Journal of Individual Psychology, 59(3), 281-291.

Joubert, C. E. (1998). Narcissism, need for power, and social interest. Psychological Reports, 82(2), 701702. 
Kalaivani, G. (2017). A study on inferiority complex of high school students in relation to their academic achievement in Vellore district. International Educational Scientific Research Journal, 3, 93-96.

Kalkan, M. (2010). Ergen romantik ilişkilerinde duygusal istismar, fiziksel istismar ve soruna yönelmeye Adlerian bir bakış: Sosyal ilgi. Anadolu Psikiyatri Dergisi, 11(3), 242-247.

Kaya, C., Tansey, T. N., Melekoğlu, M., \& Çakiroğlu, O. (2015). Stress and life satisfaction of Turkish college students. College Student Journal, 49(2), 257-261.

Kayacı, Ü., \& Özbay, Y. (2016). Üniversite öğrencilerinin travmatik yaşantı, psikolojik doğum sıraları ve sosyal ilgilerinin psikolojik dayanıklılıklarını yordaması. The Journal of Happiness $\mathcal{E}$ WellBeing, 4(1), 128-142.

Kermen, U., Tosun, N. İ., \& Doğan, U. (2016). Yaşam doyumu ve psikolojik iyi oluşun yordayıcısı olarak sosyal kaygı. Ĕ̆itim Kuram ve Uygulama Araştırmaları Dergisi, 2(1), $20-29$.

Kızıltaş, A. (2016). Üniversite öğrencilerinin saldırganlık düzeylerinin yetersizlik duyguları açısından incelenmesi. Tibbi Sosyal Bilimler Dergisi, 8, 25-35.

Köker, S. (1991). Normal ve sorunlu ergenlerin yaşam doyumu düzeylerinin karşılaştırılması. (Yüksek lisans tezi). https://tez.yok.gov.tr sayfasından erişilmiştir.

Limonero, J. T., Tomás-Sábado, J., Fernández-Castro, J., Gómez-Romero, M. J., \& Ardilla-Herrero, A. (2012). Resilient coping strategies and emotion regulation: predictors of life satisfaction. Psicol Conduct, 20(1), 183-196.

Meadows, S. O., Brown, J. S., \& Elder, G. H. (2006). Depressive symptoms, stress, and support: Gendered trajectories from adolescence to young adulthood. Journal of Youth and Adolescence, 35(1), 89-99.

Moksnes, U. K., Løhre, A., Lillefjell, M., Byrne, D. G., \& Haugan, G. (2016). The association between school stress, life satisfaction and depressive symptoms in adolescents: Life satisfaction as a potential mediator. Social Indicators Research, 125(1), 339-357.

Moritz, S., Werner, R., \& Collani G. V. (2006). The inferiority complex in paranoia readdressed: A study with the implicitassociation test. Cognitive Neuropsychiatry, 11(4), 402-415.

Özdemir, M., \& Dilekmen, M. (2016). Eğitim fakültesi öğrencilerinin duygusal zekâ ve yaşam doyumlarının incelenmesi. Sakarya University Journal of Education, 6(1), 98-113.

Özgür, G., Gümüş, A. B., \& Durdu, B. (2010). Evde ve yurtta kalan üniversite öğrencilerinde yaşam doyumu. Psikiyatri Hemşireliği Dergisi, 1(1), 25-32.

Özkaya, G. (2017). Üniversite öğrencilerinin yalnızlı düzeyleri ile umutsuzluk ve yaşam doyumu arasındaki ilişki. (Yüksek lisans tezi). https://tez.yok.gov.tr sayfasından erişilmiştir. 
Pallant, J. (2010). SPSS survival manual (4th ed.). New York, NY: McGraw Hill.

Preacher, K. J., \& Hayes, A. F. (2004). SPSS and SAS procedures for estimating indirect effects in simple mediation models. Behavior Research Methods, Instruments, \& Computers, 36(4), 717-731.

Preacher, K. J., \& Hayes, A. F. (2008). Asymptotic and resampling strategies for assessing and comparing indirect effects in multiple mediator models. Behavior Research Methods, 40(3), 879891.

Rickwood, D., Deane, F. P., Wilson, C. J., \& Ciarrochi, J. (2005). Young people's help-seeking for mental health problems. Australian E-journal for the Advancement of Mental Health, 4(3), 218-251.

Sapmaz, F., \& Doğan, T. (2012). Mutluluk ve yaşam doyumunun yordayıcısı olarak iyimserlik. Mersin Üniversitesi Ĕ̆itim Fakültesi Dergisi, 8(3), 63-69.

Saunders, S. A., \& Roy, C. (1999). The relationship between depression, satisfaction with life, and social interest. South Pacific Journal of Psychology, 11(1), 9-15.

Soyer, M. (2001). Üniversite öğrencilerinin toplumsal ilgi düzeylerinin bazı değişkenler açısından incelenmesi. (Doktora tezi). https://tez.yok.gov.tr sayfasından erişilmiştir.

Soyer, M. (2004). Toplumsal ilgi ölçeğinin uyarlanması: Geçerlik ve güvenirlik çalışmaları. Türk Psikolojik Danışma ve Rehberlik Dergisi, 3(21), 29-34.

Strano, D. A., \& Petrocelli, J. V. (2005). A preliminary examination of the role of inferiority feelings in the academic achievement of college students. The Journal of Individual Psychology, 61(1), 80-89.

Suldo, S. M., \& Huebner, E. S. (2006). Is extremely high life satisfaction during adolescence advantageous? Social Indicators Research, 78(2), 179-203.

Suldo, S. M., Thalji-Raitano, A., Hasemeyer, M., Gelley, C. D., \& Hoy, B. (2013). Understanding middle school students life satisfaction: Does school climate matter? Applied Research in Quality of Life, 8(2), 169-182.

Tabachnick, B., \& Fidell, L. (2013). Using multivariate statistics (6th ed.). Boston, MA: Pearson.

Tel, F. D., \& Sarı, T. (2016). Üniversite öğrencilerinde öz duyarlılık ve yaşam doyumu. Abant İzzet Baysal Üniversitesi Eğitim Fakültesi Dergisi, 16(1), 292-304.

World Health Organization. (1998). Programme on mental health: WHOQOL user manual (No. WHO/HIS/HSI Rev. 2012.03). World Health Organization.

Yıkılmaz, M., \& Demir-Güdül, M. (2015). Üniversite öğrencilerinde yaşamda anlam, bilinçli farkındalık, algılanan sosyoekonomik düzey ve yaşam doyumu arasındaki ilişkiler. Ege Eğitim Dergisi, 16(2), 297-315. 
Yiğit, R. (2012). Çevik kuvvet görevlilerinin benlik saygıları ile yaşam doyumu ve stresle başa çıkma tutumları arasındaki ilişkinin incelenmesi. Ahi Evran Üniversitesi Kırşehir Eğitim Fakültesi Dergisi, 13(1), 61-75.

\section{Extended Summary}

Life satisfaction, one of the indicators of an individual's health, refers to one's expectations for life and the level of satisfaction with these expectations. Previous studies revealed the importance of higher levels of life satisfaction in terms of individuals' mental health, adaptation, and academic success. Life satisfaction in university students is also important not only for their current developmental period but rather it is also crucial in terms of its effects on future periods. Examining the variables affecting the life satisfaction of university students will contribute to preventive or remedial guidance and counseling services (Yiğit, 2012). In this study, two concepts are considered as potential predictors of life satisfaction: the feeling of inferiority and social interest.

One of the important concepts of Individual Psychology is the feeling of inferiority. Experiencing excessive inferiority can sometimes cause an adverse effect, leading people to develop an inferiority complex and feel helpless instead of striving for superiority (Burger, 2006). Thus, a feeling of inferiority can lead to psychological issues (Akdoğan, 2012). However, there is a lack of study on the feeling of inferiority in Turkish undergraduate students. Therefore, investigating the relationship between the feeling of inferiority and life satisfaction will contribute to both practice and literature in terms of preventive measures of mental health.

Another variable considered in this study was social interest. The feeling of inferiority and the desire to overcome this feeling with others underlies social interest. According to Adler, people born as an inadequate creature develops with the interests and values of others (Ansbacher \& Ansbacher, 1956). The concept of social interest is considered as a two-way process for people, which includes both taking from society and giving it to society (Adler, 2004; Soyer, 2001). In this respect, we hypothesized that social interest is positively associated with life satisfaction.

In conclusion, this study examined the predictive effects of feeling of inferiority and social interest on life satisfaction of university students. In addition, this study investigated the mediating role of social interest on the association between the feeling of inferiority and life satisfaction.

The research group consisted of university students between the ages of $17-46(\bar{x}=21.9$; $\mathrm{S}=3.4)$. A total of 371 volunteer students, 85 males (22.9\%) and 286 females $(77.1 \%)$, participated in the study. Regarding grade level, $12.7 \%$ of the participants were in the first grade, $12.9 \%$ in the second grade, $21.6 \%$ in the third grade, and $52.8 \%$ in the fourth grade.

Demographic Questionnaire Form: This form was developed by the researchers to collect data about participants' gender, age, grade level, and socio-economic status. 
Social Interest Index (SII): The SII was originally developed by Greever, Tseng, and Friedland (1973), and adapted into Turkish by Soyer (2004). Turkish form of the SII consists of 52 items on a 4point Likert scale. The total score range between 0-208 points; higher scores indicate higher levels of social interest. In this study, the internal consistency coefficient was found to be .91 , which indicates that the scale is highly reliable (Pallant, 2010).

Inferiority Feeling Scale (IFS): The IFS was developed by Akdoğan and Ceyhan (2014) and includes 20 items on a 5-point Likert scale. As consistent with the purpose of this study, only total scores of the IFS were used. Higher scores indicate higher levels of inferiority. The internal consistency coefficient of the GDS was found to be .83 in this study, indicating a good reliability (Pallant, 2010).

Satisfaction with Life Scale (SWLW): This instrument was developed by Diener, Emmons, Larsen, and Griffin (1985) and adapted into Turkish by Köker (1991), and revised by Dağlı and Baysal (2016). The SWLW has five items on a 5-point Likert scale. The SWLW produces one total score; higher scores indicate higher levels of life satisfaction. In this study, the internal consistency coefficient was found to be .80 , which reveals that the scale is reliable (Pallant, 2010).

Ethical permission was obtained first before the data collection process. SPSS 22.0 package program was used to analyze the data, and a .05 significance level was taken as a basis. The analysis procedure was carried out in two steps. First, the suitability of the data set for the statistical methods was tested. The results revealed that the data set met the assumptions. Second, hierarchical regression analysis to test the hypotheses and bootstrapping procedures were employed with a 10,000 random resampling to test the mediating effect.

The first step of hierarchical regression analysis showed that the feeling of inferiority significantly and negatively predicted life satisfaction and explained $16 \%$ of the variance. In the second, social interest significantly and positively predicted life satisfaction and explained an additional $2 \%$ of the variance. Bootstrapping resampling analysis showed that when predicting life satisfaction, $95 \%$ a bias-corrected confidence interval did not include zero [-.02 and -.01]. Therefore, social interest was a significant mediator. However, it should be noted that the direct effect of the feeling of inferiority was still significant, so the mediating effect of social interest was partial.

This study examined the predictive effects of feeling of inferiority and social interest on life satisfaction and the mediator role of social interest. The results showed that the feeling of inferiority negatively predicted life satisfaction. If a person cannot cope with the feeling of inferiority, it can cause a risk for mental health and quality of life (Adler, 2004; Ansbacher \& Ansbacher, 1956). In this respect, this finding is consistent with a theoretical basis. Another finding of this study was that social interest significantly and positively predicted life satisfaction. This finding was also theoretically expected because social interest is one of the important indicators of mental health and quality of life 
(Ansbacher \& Ansbacher, 1956). Thus, as scores of social interests increased, levels of life satisfaction were escalated. The results also showed that social interest partially mediated the association between the feeling of inferiority and life satisfaction. In other words, higher levels of feeling of inferiority predicted lower levels of social interests, which in turn related to lower levels of life satisfaction. This result emphasizes the central role of social interest in predicting life satisfaction. However, the direct effects of the feeling of inferiority were still significant.

Regarding the implications of this study, the findings of this study suggest that students with higher levels of inferiority can be prior to receiving counseling services. Individual and group work and social activities can be delivered to students who experience the feeling of inferiority. In addition, designing social interest-oriented academic and social programs in educational institutions and implementing them in a planned framework may have an impact on life satisfaction of undergraduate students.

There are limitations of this study. First, the design of the study was correlational, so it is not fully possible to conclude a cause-and-effect relationship. Future longitudinal and experimental studies can be conducted. In addition, this study considered feeling of inferiority in a general manner, so future studies can focus on specific areas that students can feel inferiority. Another limitation was that majority of the participants were female, so future studies can be conducted with a sample including an equal gender rate. The findings of this study are limited to university students, so it should be cautious when generalizing the results to other populations.

\section{Araştırmacıların Katkı Oranı Beyanı}

$\mathrm{Bu}$ araştırmada, birinci yazar; araştırma dizaynı, alanyazın taraması ve giriş, veri toplama ve verilerinde düzenlenmesi, tartışma ve sonuç bölümlerine; ikinci yazar, araştırma dizaynı, verilerin analizi, yöntem, bulgular ve tartışma bölümlerine katkı sağlamıştır.

\section{Destek ve Teşekkür Beyanı}

Düzce Üniversitesi Rektörlüğü, Düzce Üniversite Eğitim Fakültesi ve Düzce Üniversitesi Rehberlik ve Psikolojik Danışmanlık Anabilim Dalına katkılarından dolayı teşekkür ederiz.

\section{Çatışma Beyanı}

Araştırmacının araştırma ile ilgili diğer kişi ve kurumlarla herhangi bir kişisel ve finansal çıkar çatışması yoktur.

\section{Etik Kurul Beyanı}

Bu araştırma, Düzce Üniversitesi Bilimsel Araştırma ve Yayın Etik Kurulunun 13.03.2020 tarih ve 2020/49 sayılı onayı ile yürütülmüştür. 